\title{
Opsoclonus-Myoclonus with Multiple Paraneoplastic Syndromes and VGCC Antibodies
}

\author{
Colin B. Josephson, Ian Grant, Timothy Benstead
}

Can. J. Neurol. Sci. 2009; 36:512-514

Current evidence suggests that neurological paraneoplastic syndromes are clinical entities in which antibodies directed against tumor epitopes cross-react with native antigens within the nervous system ${ }^{1,2}$. Recent evidence suggests that many antibodies are not exclusively associated with a particular syndrome, and that particular antibodies may be more indicative of the underlying malignancy than a specific neurological disorder ${ }^{3}$. They may serve a protective role in controlling neoplastic growth and spread as the neurological syndrome almost always appears (up to months or years) prior to identification of the underlying tumor ${ }^{4,5}$.

Symptomatic paraneoplastic syndromes occur in less than $1 \%$ of patients with cancer. However, rates of up to 3-20\% have been reported in patients with small cell lung cancer (SCLC), thymomas, and B-cell or plasma-cell malignancies ${ }^{2,6}$. Cases of multiple paraneoplastic syndromes in a single patient are very rare. In this case report we present a patient who concurrently developed Lambert-Eaton Myasthenic Syndrome (LEMS), subacute cerebellar degeneration (SCD), and opsoclonusmyoclonus syndrome (OMS).

\section{Case Report}

The patient was a 48 -year-old male who initially presented with a raised nodular lesion on the anterior aspect of his right leg. Biopsy revealed a well-differentiated superficially invasive squamous cell carcinoma. The lesion was excised using wide margins and a split thickness skin graft. He had an uncomplicated initial post-operative recovery but within a few months noticed ongoing weight loss (approximately $15 \mathrm{~kg}$ since the operation), shortness of breath and fatigue. He sought medical attention and a mass was identified on the right side of his neck. A computed tomogram (CT) scan demonstrated a rightsided supraclavicular mass, a right upper lobe mass, and bilateral hilar lymphadenopathy. Biopsy of the right supraclavicular mass revealed limited stage SCLC. Computed tomography of the brain and magnetic resonance imaging of the spine were normal. He received a three-day course of chemotherapy with etoposide $\left(100 \mathrm{mg} / \mathrm{m}^{2}\right)$ and cisplatin $\left(25 \mathrm{mg} / \mathrm{m}^{2}\right)$. Three months following chemotherapy he received prophylactic whole brain irradiation.

Six months later he acutely developed nausea, vomiting, and vertigo. He was admitted to his local hospital and diagnosed with vestibular neuronitis. Over the next two weeks he complained of double vision, visual blurring and "jumping", and difficulties swallowing. He reported significant problems with limb incoordination. He did not describe sensory changes, dry mouth or other autonomic symptoms. The attending physicians reported nystagmus, dysarthria, hypophonia, myoclonus, and ataxia on

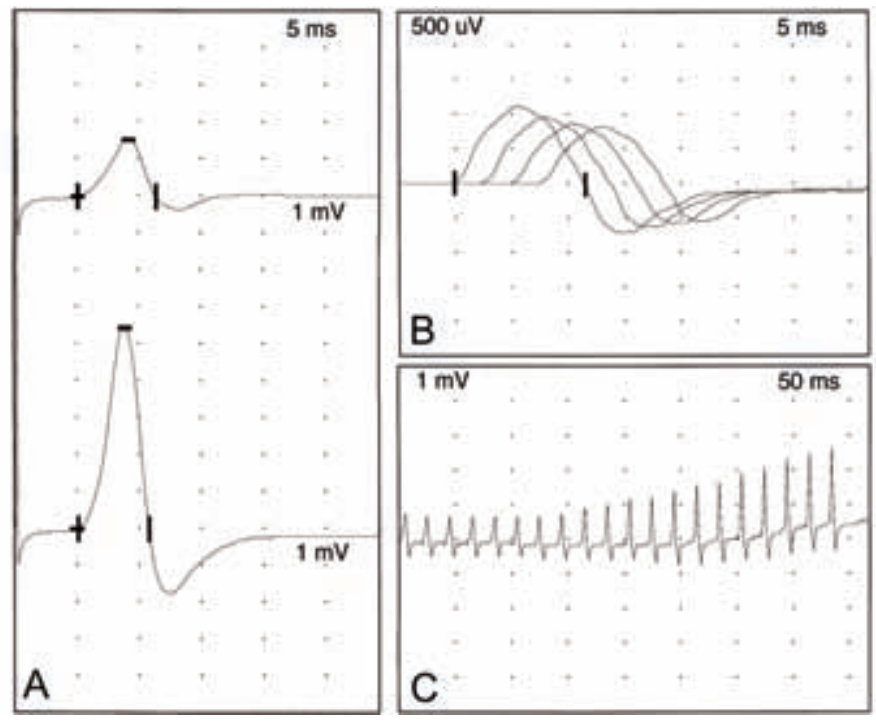

Figure: A) A supramaximal stimulus was given to the tibial nerve at the ankle recording over the abductor hallucis muscle. The top trace was before exercise and the bottom trace immediately after a ten second tetanic contraction of the muscle. B) A supramaximal stimulus was given at $2 \mathrm{~Hz}$ to the right peroneal nerve at the knee recording over the anterior tibial muscle. The decrement between the 1st and 4th CMAP responses was $25 \%$. C) A supramaximal stimulus was given at $50 \mathrm{~Hz}$ to the ulnar nerve recording over the hypothenar muscle. Twenty responses were recorded demonstrating an incremental response of $183 \%$.

exam. Computed tomogram of the brain was reported as normal. Given the rapid progression of symptoms and lack of response to treatment (betahistidine, dexamethasone, and ondansetron), he was transferred to the Queen Elizabeth II Health Sciences Centre for further investigations.

On transfer he was no longer able to ambulate because of severe imbalance. Examination of the cranial nerves revealed bilateral opsoclonus, ocular ataxia, right-beating nystagmus on right gaze and dysarthric staccato speech. Motor exam revealed

From the Division of Neurology, Department of Medicine, Dalhousie University, Halifax, Nova Scotia, Canada.

Received January 19, 2009. Final Revisions Submitted March 9, 2009. Correspondence to: Timothy Benstead, Dalhousie University, Department of Medicine, Division of Neurology, Room 3828 Halifax Infirmary, Queen Elizabeth II Health Sciences Centre, 1796 Summer Street, Halifax, Nova Scotia, B3H 3A7, Canada. 
generalized mild muscular atrophy and myoclonus, but extremity strength was not significantly reduced. He was areflexic with flexor plantar responses. Bilateral intention tremor was present. Dysmetria was observed on finger-to-nose testing and heel-toshin testing. Rapid alternating movements were impaired. Sitting balance was impaired with a propensity for falling to the left side. Romberg and gait could not be tested because of profound ataxia.

Complete blood count revealed a normocytic anemia $($ Hemoglobin $=112 \mathrm{~g} / \mathrm{L}$, Mean cell volume $=93.3 \mathrm{fL})$. Electrolytes, renal and liver function tests, thyroid stimulating hormone, free thyroxine, vitamin $\mathrm{B}_{12}$ and folate were normal. Erythrocyte sedimentation rate $(40 \mathrm{~mm} / \mathrm{HR})$ and C-reactive protein $(9.22 \mathrm{mg} / \mathrm{L})$ were elevated. Anti-nuclear and extractable nuclear antibodies (dsDNA, chromatin, ribosomal P, SS-A/Ro, SS-B/La, centromere B, Sm, Sm/RNP, Scl-70, and Jo-1) were negative. Rheumatoid factor was not detected. Complement levels (C3 and C4) were normal. Unenhanced and gadoliniumenhanced MRI sequences of the brain revealed cerebellar atrophy. Thoracic CT did not reveal definitive evidence of a neoplasm. 2-fluoro-2-deoxy-D-glucose positron emission tomography scanning was not available for patient assessment.

Nerve conduction studies revealed diffusely small compound muscle action potential (CMAP) amplitudes ranging from 12 to $88 \%$ of the lower limit of normal. All other motor nerve conduction parameters and $\mathrm{F}$ wave latencies were normal. Sensory nerve conduction parameters were normal. An EMG was requested to assess whether neuropathy was contributing to the ataxia. The evaluation was not suggestive of a demyelinating polyneuropathy or sensory neuronopathy as a cause for this problem. As small CMAP amplitudes were the only abnormality on routine studies, LEMS was considered and studies with brief tetanic exercise as well as repetitive nerve stimulation were performed. A ten second tetanic exercise produced increment of the CMAP amplitude in the right median (117\%), tibial (243\%), peroneal to anterior tibial $(70 \%)$ and ulnar $(575 \%)$ nerves (Figure A). Repetitive stimulation $(2 \mathrm{~Hz})$ of the ulnar nerve recording over the hypothenar eminence and the peroneal nerve recording over the anterior tibial muscle revealed significant decrement (range 25 to $37 \%$ ) (Figure B). Repetitive stimulation at $50 \mathrm{~Hz}$ revealed a $183 \%$ increment after 20 stimuli in the right ulnar nerve when recording over the hypothenar eminence (Figure C). Needle electromyography revealed small motor unit potentials with moment-to-moment variation in configuration suggestive of a neuromuscular junction defect. The electrodiagnostic changes were consistent with a presynaptic neuromuscular junction disorder, with features typical of LEMS.

Paraneoplastic antibodies were assessed at the Mayo Medical Laboratories using immunofluorescence, enzyme-linked immunosorbant assay, radioimmunoprecipitation, and western blot analysis. P/Q-type calcium channel antibodies were detected at a titre of $0.14 \mathrm{nmol} / \mathrm{L}$ (negative $\leq 0.02 \mathrm{nmol} / \mathrm{L}$ ). Additional antibodies associated with subacute cerebellar degeneration (PCA-Tr, PCA-1/anti-Yo, PCA-2, AGNA-1, ANNA-1/anti-Hu, CRMP-5-IgG), opsoclonus-myoclonus (anti-Ri/ANNA-2), and other paraneoplastic syndromes (amphiphysin antibody, ACh receptor [muscle] binding antibody, striational [striated muscle] antibody, N-Type calcium channel antibody, ANNA-3, AChR ganglionic antibody, neuronal antibody, and neuronal (V-G) K+ antibody) were not detected.
The patient was diagnosed with concurrent LEMS, SCD, and OMS. Chemotherapy was not indicated given the lack of convincing radiological evidence of recurrent cancer. The patient was treated with intravenous immunoglobulin $(0.4 \mathrm{~g} / \mathrm{kg} / \mathrm{d})$ for five days. Pyridostygmine (30 $\mathrm{mg}$ po tid) and 3,4diaminopyridine (20 $\mathrm{mg}$ po qid) were used to control LEMSrelated symptoms. A percutaneous gastrostomy tube was ultimately required. The patient responded well to therapy but still required a wheelchair due to residual ataxia at the time of discharge.

\section{Discussion}

Neurologic paraneoplastic syndromes are relatively rare conditions. Multiple simultaneous syndromes have been previously reported in only a few patients ${ }^{7-10}$. To our knowledge, concurrent OMS, SCD, and LEMS have not been reported. Anti$\mathrm{P} / \mathrm{Q}$ calcium channel antibodies have been reported in both LEMS $^{11-17}$ and SCD ${ }^{12,18-20}$ and in cases of concomitant LEMS and $\mathrm{SCD}^{12,21-24}$ but not in OMS. A recently identified paraneoplastic antibody, anti-glial nuclear antibody, was included as a part of the screen ${ }^{25}$. This autoantibody targets the nuclei of Bergmann glia located in the cerebellum. Specifically, it reacts with SOX1, a highly immunogenic tumor antigen expressed by $\mathrm{SCLC}^{26}$. Its presence has been associated with LEMS in the context of SCLC but was not detected in the serum of our patient ${ }^{25,26}$.

Our ability to detect residual or recurrent tumor would have been improved with access to positron emission tomography scanning. A recent retrospective review of 104 patients with suspected paraneo-plastic syndrome demonstrated improved neoplastic detection rates with positron emission tomography scanning (8/10 pathologically confirmed malignancies detected) compared to $\mathrm{CT}$ scanning (3/10 pathologically confirmed malignancies detected). Sensitivity, specificity, positive predictive value, and negative predictive values were $80 \%, 67 \%$, $53 \%$, and $88 \%$ respectively ${ }^{27}$.

The patient's cerebellar degeneration was unlikely to be related to radiation. Current data suggests that there is no significant difference in neuropsychological outcomes or in the rate of $\mathrm{CT}$ brain abnormalities detected between patients with SCLC who were treated with prophylactic whole brain irradiation compared to those who were not treated ${ }^{28}$.

The etiology of the patient's OMS remains undetermined. It is possible that one antibody may cause multiple neurological paraneoplastic syndromes. Animal models suggest that $\mathrm{P} / \mathrm{Q}$ VGCC knock-out mutations (CACNA1A gene) result in subnormal gains with high-frequency stimuli in tests of the angular vestibuloocular reflex. Minimally reduced gains were recorded in horizontal optokinetic responses ${ }^{29}$. Likewise, excessive intracellular calcium, as suggested by decreased sarcoplasmic reuptake rates, has been postulated as a pathophysiological mechanism in primary inferior oblique overactivation $^{30}$. However, mutations in the CACNA1F gene (which codes for the $\alpha 1$-subunit of the L-type voltage gated calcium channel [VGCC]) are associated with nystagmus as a part of incomplete congenital stationary night blindness syndrome ${ }^{31}$. However, a specific paraneoplastic antibody is not found in the majority of patients presenting with acquired $\mathrm{OMS}^{32}$. Thus it remains unclear as to what role, if any, anti-VGCC antibodies would play in opsoclonus. 
Squamous cell carcinomas rarely produce neurological paraneoplastic syndromes. In our patient the SCLC was probably responsible for inducing antibody production given its frequent association with neurological paraneoplastic disorders and the timing of the paraneoplastic symptoms in relation to the diagnosis of lung cancer. Small cell lung carcinoma is correlated with the presence of anti-VGCC antibodies ${ }^{33}$. Anti-VGCC antibodies block inward calcium currents in SCLC cell lines ${ }^{34}$ and their presence improves disease prognosis ${ }^{35}$. There are also associations between LEMS and central nervous system paraneoplastic disorders, an observation supported by the presence of antibodies in CSF of some patients with combined SCD, LEMS, and SCLC ${ }^{17,18,22}$.

\section{REFERENCES}

1. Graus F, Dalmau J. Paraneoplastic neurological syndromes: diagnosis and treatment. Curr Opin Neurol. 2007;20:732-7.

2. Darnell RB, Posner JB. Paraneoplastic syndromes involving the nervous system. N Engl J Med. 2003;349:1543-54.

3. Pittock SJ, Kryzer TJ, Lennon VA. Paraneoplastic antibodies coexist and predict cancer, not neurological syndrome. Ann Neurol. 2004;56:715-19.

4. Peterson K, Rosenblum MK, Kotanides H, Posner JB. Paraneoplastic cerebellar degeneration. I. A clinical analysis of 55 anti-yo antibody-positive patients. Neurology. 1992;42:1931-7.

5. Graus F, Keime-Guibert F, Rene R, Benyahia B, Ribalta T, Ascaso C, et al. Anti-hu-associated paraneoplastic encephalomyelitis: analysis of 200 patients. Brain. 2001;124:1138-48.

6. Dalmau J, Rosenfeld MR. Paraneoplastic syndromes of the CNS. Lancet Neurol. 2008;7:327-40.

7. Nagashima T, Mizutani Y, Kawahara H, Maguchi S, Terayama Y, Shinohara T, et al. Anti-hu paraneoplastic syndrome presenting with brainstem-cerebellar symptoms and Lambert-Eaton myasthenic syndrome. Neuropathology. 2003;23:230-8.

8. Sa G, Correia C, Pires M, Lopes G. Multiple paraneoplastic syndromes occurring in the same patient: clinical, imaging and neuro-pathological documentation. Acta Med Port. 2006;19: 489-93.

9. Heidenreich F, Schober R, Brinck U, Hartung HP. Multiple paraneoplastic syndromes in a patient with antibodies to neuronal nucleoproteins (anti-hu). J Neurol. 1995;242:210-16.

10. Hiasa Y, Kunishige M, Mitsui T, Kondo S, Kuriwaka R, Shigekiyo S, et al. Complicated paraneoplastic neurological syndromes: a report of two patients with small cell or non-small cell lung cancer. Clin Neurol Neurosurg. 2003;106:47-9.

11. Lennon VA, Kryzer TJ, Griesmann GE, O'Suilleabhain PE, Windebank AJ, Woppmann A, et al. Calcium-channel antibodies in the Lambert-Eaton syndrome and other paraneoplastic syndromes. N Engl J Med. 1995;332:1467-74.

12. Fukuda T, Motomura M, Nakao Y, Shiraishi H, Yoshimura T, Iwanaga K, et al. Reduction of P/Q-type calcium channels in the postmortem cerebellum of paraneoplastic cerebellar degeneration with lambert-eaton myasthenic syndrome. Ann Neurol. 2003;53:21-8.

13. Lang B, Dale RC, Vincent A. New autoantibody mediated disorders of the central nervous system. Curr Opin Neurol. 2003;16:351-7.

14. Lang B, Newsom-Davis J. Immunopathology of the lambert-eaton myasthenic syndrome. Springer Semin Immunopathol. 1995;17: 3-15.

15. Motomura M, Lang B, Johnston I, Palace J, Vincent A, NewsomDavis J. Incidence of serum anti-P/O-type and anti-N-type calcium channel autoantibodies in the lambert-eaton myasthenic syndrome. J Neurol Sci. 1997;147:35-42.

16. Takamori M, Maruta T, Komai K. Lambert-Eaton myasthenic syndrome as an autoimmune calcium-channelopathy. Neurosci Res. 2000;36:183-91.
17. Voltz R, Carpentier AF, Rosenfeld MR, Posner JB, Dalmau J. P/Qtype voltage-gated calcium channel antibodies in paraneoplastic disorders of the central nervous system. Muscle Nerve. 1999;22:119-22.

18. Graus F, Lang B, Pozo-Rosich P, Saiz A, Casamitjana R, Vincent A. $\mathrm{P} / \mathrm{Q}$ type calcium-channel antibodies in paraneoplastic cerebellar degeneration with lung cancer. Neurology. 2002;59:764-6.

19. Liao YJ, Safa P, Chen YR, Sobel RA, Boyden ES, Tsien RW. Anti$\mathrm{Ca} 2+$ channel antibody attenuates $\mathrm{Ca} 2+$ currents and mimics cerebellar ataxia in vivo. Proc Natl Acad Sci USA. 2008;105: 2705-10.

20. Trivedi R, Mundanthanam G, Amyes E, Lang B, Vincent A. Autoantibody screening in subacute cerebellar ataxia. Lancet. 2000;356:565-6.

21. Nakamura M, Yabe I, Sato K, Nakano F, Yaguchi H, Tsuji S, et al. Transient subacute cerebellar ataxia in a patient with lamberteaton myasthenic syndrome after intracranial aneurysm surgery. Clin Neurol Neurosurg. 2008;110:480-3.

22. Clouston PD, Saper CB, Arbizu T, Johnston I, Lang B, NewsomDavis J, et al. Paraneoplastic cerebellar degeneration. III. Cerebellar degeneration, cancer, and the lambert-eaton myasthenic syndrome. Neurology. 1992;42:1944-50.

23. Lorenzoni PJ, Scola RH, Lang B, Kay CS, Teive HA, Kowacs PA, et al. Cerebellar ataxia in non-paraneoplastic lambert-eaton myasthenic syndrome. J Neurol Sci. 2008;270:194-6.

24. Mason WP, Graus F, Lang B, Honnorat J, Delattre JY, Valldeoriola F, et al. Small-cell lung cancer, paraneoplastic cerebellar degeneration and the lambert-eaton myasthenic syndrome. Brain. 1997;120 (Pt 8):1279-300.

25. Graus F, Vincent A, Pozo-Rosich P, Sabater L, Saiz A, Lang B, et al. Anti-glial nuclear antibody: marker of lung cancer-related paraneoplastic neurological syndromes. J Neuroimmunol. 2005; 165:166-71.

26. Sabater L, Titulaer M, Saiz A, Verschuuren J, Gure AO, Graus F. SOX1 antibodies are markers of paraneoplastic lambert-eaton myasthenic syndrome. Neurology. 2008;70:924-8.

27. Patel RR, Subramaniam RM, Mandrekar JN, Hammack JE, Lowe VJ, Jett JR. Occult malignancy in patients with suspected paraneoplastic neurologic syndromes: value of positron emission tomography in diagnosis. Mayo Clin Proc. 2008;83: 917-22.

28. Prophylactic Cranial Irradiation Overview Collaborative Group. Cranial irradiation for preventing brain metastases of small cell lung cancer in patients in complete remission. Cochrane Database Syst Rev. 2000;(4):CD002805.

29. Stahl JS. Eye movements of the murine P/Q calcium channel mutant rocker, and the impact of aging. J Neurophysiol. 2004;91: 2066-78.

30. Kim HS, Chang YH, Kim DH, Park SR, Han SH, Lee JB. Calcium uptake and release through sarcoplasmic reticulum in the inferior oblique muscles of patients with inferior oblique overaction. Yonsei Med J. 2006;47:207-13.

31. Gottlob I. Nystagmus. Curr Opin Ophthalmol. 2001;12:378-83.

32. Bataller L, Graus F, Saiz A, Vilchez JJ, Spanish OpsoclonusMyoclonus Study Group. Clinical outcome in adult onset idiopathic or paraneoplastic opsoclonus-myoclonus. Brain. 2001;124:437-43.

33. Oguro-Okano M, Griesmann GE, Wieben ED, Slaymaker SJ, Snutch TP, Lennon VA. Molecular diversity of neuronal-type calcium channels identified in small cell lung carcinoma. Mayo Clin Proc. 1992;67:1150-9.

34. Roberts A, Perera S, Lang B, Vincent A, Newsom-Davis J. Paraneoplastic myasthenic syndrome $\mathrm{IgG}$ inhibits $45 \mathrm{Ca} 2+$ flux in a human small cell carcinoma line. Nature. 1985;317:737-9.

35. Maddison P, Newsom-Davis J, Mills KR, Souhami RL. Favourable prognosis in lambert-eaton myasthenic syndrome and small-cell lung carcinoma. Lancet. 1999;353:117-18. 